\title{
The need for fundamental change in Education
}

\section{Salim Lardjane, Françoise Laveuve, Mari Nuutinen}

Envigogika 12 (2) - Inspiration/ Inspirace

Publikováno/Published dne 15. 11. 2017

DOI: $10.14712 / 18023061.552$

\section{Introduction}

In the Unescopress document of September 6th, 2016, UNESCO reminds us that Education must change in order to achieve the Goals of the Global Action Program.

UNESCO's new report on World Education Monitoring shows the great potential of education to promote progress towards the global goals set out in the new Agenda 2030 for Sustainable Development Goals (SDGs). It also shows that education needs a major transformation to realize this potential and to meet the current challenges that humanity and the planet are facing.

"A fundamental change is needed in the way we think about the role of Education in global development because it has a catalytic impact on the well-being of individuals and the future of our planet," said Irina Bokova, Director-General of UNESCO. "Now more than ever, Education has a responsibility to be in step with the challenges and aspirations of the 21st century, and to foster the values and skills that will lead to a sustainable and inclusive growth and a peaceful life together".

\section{For quality education}

Thus UNESCO has identified key criteria for improving the quality of education at the level of the learner and the education system itself. For example, the diversity of teaching techniques is necessary because it helps students to develop and apply different learning processes, allowing them to appropriate the method that best suits them, thereby improving their skills and ability to think and learn. Indeed, students in one class do not all have the same learning abilities, and some find it difficult to comply with the educational standards defined for all by the Educational Institution. Some students learn by listening and memorizing, others need to rely on reading, still others need to experiment in order to understand and assimilate. Responding to the learning modalities of all students in a class has become essential; it is a form of social equity, a key concept of sustainable development (Nuutinen, 2007). Indeed, the school drop-out rate, which is most often linked to an inadequacy in relation to the current single learning model, is a real major problem for social and economic sustainability. The use of diversified teaching practices meets the learning needs of all students in a class. 


\section{Pedagogies for Education for Sustainable Development}

\section{How can Education lead to sustainability? Transformative Education}

When we talk about sustainability, we talk about our planet, about life on the planet, and about the sustainable future of the planet. We talk about education, about learning and about teaching practices which must be of high quality, and also about the way we have to transform our education into Sustainable Development. A sustainable future is possible only by solving current problems and through coherent decision-making.

What skills do we need from now on? The research focuses on resilience, systemic intelligence and forecasts, but also empathy, compassion and consideration for all. It is important to allow learners to realize their respective individual potential; what is essential to lead whole communities towards a positive social transformative process. So, tranformative education will help the learner to learn instead of only being taught by the teacher. Transformative education requires students to examine their own mental patterns and their "sustainability" within their own context of life and in light of their well-being. It is a matter of development and individualisation. In this way, the students can become fully-fledged persons. This principle of transformative learning gives great responsibility to the learner as well as to the person who assists transformative learning since the traditional principles of simple transmission of knowledge by the teacher and memorization of information by students are no longer appropriate. The traditional principle which holds that only intelligence allows one to solve problems is no longer adequate.

In transformative learning, when the central problem of concern is solved, the question arises as to what to focus on, how to define what is important to oneself and what is capable of being engaged in the sector under consideration. Learning to take care of something is natural and transformational. Our self-perception is modified, it reveals what we aspire to, which is within us, whatever the circumstances. When we take care of what is important to us, we are in a state of well-being.

Transformative learning, which is a learning process because it takes into account thought, feeling and will, is the natural path to a sustainable future. Transformative learning is no doubt compatible with the development of strong and positive leadership. That well-being is based not only on a sense of understanding, management and the notion of competence, but also on a sense of autonomy, the meaning given to things, and the relationships necessary in our business. In this way, it is possible to talk about leadership, sustainability and well-being in a coherent learning context. (cf. Suni and Nuutinen, 2012)

\section{The OPEDUCA concept}

Schools are therefore important places to promote a sustainable and well-being oriented lifestyle in daily culture.

The OPEDUCA concept made this its basic principle. It was developed in association with the direction of educators, teachers, scientists, entrepreneurs, politicians and all other actors in education who can contribute to the radical transformation of school and the world of education. The term "OPEDUCA" represents both this network and its actions, as well as a vision of learning translated into concrete tools and activities that can be implemented structurally in educational practice. With Education for Sustainable 
Development as a guideline, the OPEDUCA concept leads to improvement in the quality of education in various dimensions and in all subjects. The capacity of young people to transform their ideas into action, and, in so doing, to develop their knowledge and skills (spirit of initiative, communication, presentation of their work), is an integral part of the OPEDUCA project.

The term OPEDUCA is an abbreviation of "Open Educational Area", i.e. a region where people and organizations are connected and carry out actions in agreement with each other so that processes of integrated education are put in place, linking theory, practice and experience.

Within the framework of Education for Sustainable Development, the OPEDUCA project implements many new pedagogies to meet the learning needs of students, and to introduce equity into the classroom. In this way, students learn how equity and social sustainability work. A comprehensive school approach to sustainable development also promotes the principles of sustainable development (Saloranta, 2017). Another form of equity inherent to sustainability and practiced in the classroom is gender. ESD and / or ESD pedagogies encourage students to ask questions, analyze, practice critical thinking and make decisions. It is a participatory learning process that encourages social criticism and analysis of local situations. It is based on discussion, analysis and respect for values. Pupils' responsiveness is stimulated, as ESD pedagogies work for positive change and help students develop a sense of social justice and their own effectiveness as members of a community. Moreover, the diversity of teaching techniques favors different learning processes.

\section{The reasons for the OPEDUCA project}

In the practice of education some innovations do exist, but they are disparate, with no coherent link between them. For example, schools undertake temporary projects or bring in expensive consultants, which results in fragmented action, but not a sustainable solution. Holistic action is therefore needed to link together the key elements of a better education.

It is therefore a question of working towards a labor market-oriented education which requires a more scientifically qualified and competent next generation that demonstrates both basic competences and cross-curricular competences at a higher level, and is capable of turning ideas into actions as entrepreneurs of the future. Consequently, the project addresses the challenges and priorities necessary for the implementation of a "Rethought Education".

Schools must now start and be open to more targeted and rapid development of education in order to meet the needs and expectations of the labor market. The main objective of this project is to merge schools and the world of work. To adapt knowledge and skills to labor market requirements in a clearer and more direct way, the project plans to define and test approaches in many regions of the $\mathrm{EU}$, thus creating open educational regions (OPEDUCA). Regions across Europe where schools, industry, science and governments continue to cooperate as partners in education. It is a multi-stakeholder regional approach toward politicians, school management and industry leaders.

\section{The advantage of the heuristic map technique in the OPEDUCA project}

Tony Buzan, an English psychologist, is the creator of the concept of the "heuristic map", a diagram that represents the semantic connections between different ideas and the 
hierarchical links between different intellectual concepts. This diagram is also known as mind mapping or "mental map" (Buzan, 2005a; Buzan, 2005b).

A mental map is an effective graphic technique that provides a universal key allowing one to unlock the potential of the brain. It exploits the full range of cortical skills words, images, logic, rhythm, color and spatial awareness. In general, because it is a valuable aid in areas such as thinking, memorization, concentration, and organization of ideas, it improves student learning in various school disciplines. Because it arises from the basic structure of the brain, this method greatly improves the mental faculties that everyone has (Buzan and Buzan, 2010).

It has been established that the use of a heuristic map helps pupils and students not only to organize their ideas, but to have a better understanding of the concepts involved. A traditional sequential plan of work may prove problematic for certain types of pupils or students, and so a mental map suits them better because it permits a non-linear organization of information, and is freer and presents a visual approach to the data that is easier to grasp than a written text (Wheeldon and Ahlberg, 2012; IARE, 2003).

In general, a mental map facilitates the comprehension of a subject and the memorization of the information related to it; it improves thinking, facilitates the analysis of a problem, makes it possible to synthesize and put research results in a defined order to find solutions, and ultimately increases the success rate of pupils and students in examinations (Budd, 2004; Chiou, 2008; Ahlberg, 2013; CRDP Toulouse, 2013).

\section{The OPEDUCA project involved in the future of the learning for Sustainable Development}

The first United Nations Decade of Education for Sustainable Development (ESD), which took place from 2005 to 2014 (UNESCO, 2014), was followed by the Global Action Plan (GAP) in ESD, which focused on the extension of the actions and best practices in the field. UNESCO was the lead Agency for the Decade nominated by the United Nations General Assembly, and is now leading the implementation of GAP in accordance with United Nations General Assembly Resolution A / RES / 69/211.

According to Resolution $37 \mathrm{C} / 12$ approved by the General Conference of UNESCO, the GAP "will be established for an initial period of five years, after which it will be examined for a possible extension". The current GAP framework will therefore come to an end in 2019, and UNESCO Member States will soon have a decision to make on the postGAP period. To this end, the UNESCO Secretariat is launching consultation processes to think about the post-GAP period, and the future orientation of education and sustainable development in general (UNESCO, 2015; 2016; 2017).

Much of the guidance and strategic decisions made earlier remain valid, but their relevance and effectiveness may need to be reviewed in relation to emerging developments in the world, including but not limited to:

\section{1) Sustainable Development as a way of life:}

Young people in particular are addressing the issue of sustainability in their choice of a specific way of life and a commitment to certain values. ESD, implemented as education on environmental challenges or related challenges, does not speak to them effectively. 


\section{2) Education for knowledge and skills in relation to education for values and empowerment:}

Sustainable development requires much more than specific knowledge and skills. Education for sustainable development must therefore go beyond the emphasis on knowledge and skills, and promote values and attitudes conducive to sustainable development. It must be a holistic and humanistic education that must endeavor to empower people so that they can make their own choices for sustainable development. Current educational systems focusing on individual subjects and specialized knowledge are not adapted to this task of empowerment.

\section{3) Technological advances and Education:}

In the age of the Internet, learning can be done everywhere, and at any time, as learners themselves become more and more the central agent for obtaining and analyzing information and knowledge. This requires a revision of the role of formal education, and more specifically of the role of teachers. The role of formal education in the transmission of knowledge is thereby reduced. Formal education can now focus more on developing critical thinking skills as well as "the whole person". On the other hand, the boundary between formal and non-formal education is becoming more and more blurred today.

\section{4) Technological solutions for Sustainable Development:}

Technological advances (for example, smart cities) are beginning to resolve some of the "old" issues of sustainable development, thus exceeding the effectiveness of educational efforts to change people, their attitudes and behaviors. This reduces the need for education to concern itself with simple behavioral change.

\section{5) The approach to citizenship and the importance of the community:}

In many countries, ESD messages are increasingly integrated into citizenship actions that take place outside the formal education system. The sphere of life in and for the community, beyond the walls of the school, becomes the major platform for action for ESD.

\section{6) Developing countries and developed countries:}

Choosing a sustainable lifestyle can differ greatly in developed and developing countries. Young people in developing countries with high unemployment rates may not be able to afford to make a sustainable "lifestyle choice" given their urgent need to earn a living. The promotion of ESD must take these differences into account.

\section{7) Sustainable Development Goals (SDG):}

With the launch of the 17 sustainable development goals, education can be expected to contribute to the achievement of all global goals. This underlines the need to broaden the perspective of current ESD programs, which have so far focused mostly on only a few specific thematic areas (e.g. climate change, disaster risk reduction, biodiversity). A broader partnership and closer cooperation with key stakeholders will be needed. 


\section{Conclusion}

In conclusion, education can be said to be the key to a better and more sustainable future for present and future generations. Education for Sustainable Development - a key factor and catalyst for sustainable development - has paved the way for a growing number of learners, educators, decision-makers and other stakeholders who recognize the importance of collective responsibility to meet global challenges and build more sustainable and resilient societies.

Learning a sustainable lifestyle is a long-term undertaking that requires the attention and participation of all. In order to move towards a sustainable and just world, without leaving anyone behind, Member States and other stakeholders (according to the Director-General of the United Nations Educational, Scientific and Cultural Organization on the implementation of Education for Sustainable Development, at the United Nations General Assembly of 13 July 2017) "should continue to strengthen education for Sustainable Development by implementing the five priority areas of action of the Global Action Program - policies, learning environments, educators, youth and local communities - by encouraging and supporting education for Sustainable Development in all countries."

\section{Acknowledgement}

For more detailed information on the OPEDUCA Project, see: www.opeduca.eu. The OPEDUCA Project - Developing Open Educational Regions for Future-Oriented Learning and Teaching Anytime, Anyplace, with Anybody, through Any Device, 540384-LLP-1-20131-NL-COMENIUS-CMP.

\section{Bibliography}

- Ahlberg, M. (2013) Concept mapping as an empowering method to promote learning, thinking, teaching and research. Journal for Educators, Teachers and Trainers, Vol. 4 (1), pp.25-35.

- $\quad$ Budd.J.W. (2004) Mind maps as classroom exercices. The Journal of Economic Education, 25(1), 35-46.

- Buzan, T. (2005a) The Ultimate Book of mind maps, Thorsons.

- Buzan, T. (2005b) Mind map Handbook, Thorsons.

- Buzan, T. and Buzan, B. (2010) Mind map: Dessine-moi l'intelligence, Eyrolles/BBC.

- Chiou, C.C. (2008) The effect of concept mapping on students' learning achievements and interests. Innovations in Education and teaching International, $45(4), 375-387$.

- C.R.D.P. de Toulouse (2013) Usages pédagogiques des cartes mentales.

- $\quad$ Institute for the Advancement of Research in Education (IARE) at AEL, 2003. Graphic organizers: A Review of Scientifically Based Research. Charleston, WV. 
- Nuutinen, A.M. (2007) Master thesis: How did the fifth graders master core concept of biology in SCIS program. Faculty of Behavioral Sciences. Department of Applied Sciences of Education. University of Helsinki.

- Saloranta, Seppo (2017) Doctoral Thesis: "The importance of a school's culture in implementing Education for Sustainable Development in Basic Education grades 16 Schools"

- UNESCO (2014) Shaping the Future We want: UN Decade of Education for Sustainable Development (2005-2014) Final Report. UNESCO.

- UNESCO (2015) Rapport mondial de suivi sur l'Education Pour Tous. UNESCO

- UNESCO (2016) Global Education Monitoring Report (GEM Report). UNESCO

- UNESCO (2017) Rapport de la Directrice Générale de I'UNESCO sur la mise en oeuvre de l'éducation au service du développement durable (72è session de I'Assemblée Générale des Nations Unies, Point 20 de l'ordre du jour: Développement Durable. NATIONS UNIES

- Wheeldon, J. and Ahlberg, M.K. (2012) Vizualizing Social Science Research, Sage.

Salim Lardjane - RCE Bretagne and Université de Bretagne Sud, LMBA UMR CNRS 6205, France

Françoise Laveuve - RCE Bretagne, France

Mari Nuutinen - RCE Espoo, Finland 